\title{
Correction to: The value of postmortem computed tomography in paediatric natural cause of death: a Dutch observational study
}

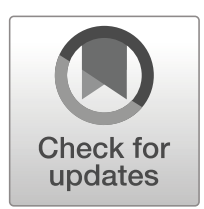

\author{
Rick R. van Rijn ${ }^{1}$ • Erik J. Beek ${ }^{2}$ • Elise M. van de Putte ${ }^{3}$ - Arianne H. Teeuw ${ }^{4}$ • Peter G. J. Nikkels ${ }^{5}$. Wilma L. J. M. Duijst ${ }^{6}$. \\ Rutger-Jan A. Nievelstein ${ }^{2}$. Dutch NODO Group
}

Published online: 13 March 2019

(C) Springer-Verlag GmbH Germany, part of Springer Nature 2019

\section{Correction to: Pediatr Radiol (2017) 47:1514-1522 \\ https://doi.org/10.1007/s00247-017-3911-0}

When first published, this article inadvertently listed the Dutch NODO group individually within the author list without specifying the names of the collaborators. The collaborators have been listed within the Acknowledgements section only. The corrected author list is presented in this Correction.

The collaborators of the Dutch NODO group are:

- Jelle Doosje (GGD GHOR, the Netherlands).

- Mrs. Esther Edelenbos (Department of Paediatrics, Free University Medical Center, Amsterdam, the Netherlands).

- Willem Fetter (Department of Paediatrics, Free University Medical Center, Amsterdam, the Netherlands).

The online version of the original article can be found at https://doi.org/ 10.1007/s00247-017-3911-0

Rick R. van Rijn

r.r.vanrijn@amc.uva.nl

1 Department of Radiology, Emma Children's Hospital, Academic Medical Centre Amsterdam, Meibergdreef 9, 1105 AZ Amsterdam, Zuid-Oost, the Netherlands

2 Department of Radiology, Wilhelmina Children's Hospital, University Medical Centre Utrecht, Utrecht, the Netherlands

3 Department of Paediatrics, Wilhelmina Children's Hospital, University Medical Centre Utrecht, Utrecht, the Netherlands

4 Department of Paediatrics, Emma Children's Hospital, Academic Medical Center Amsterdam, Amsterdam, the Netherlands

5 Department of Pathology, Wilhelmina Children's Hospital, University Medical Centre Utrecht, Utrecht, the Netherlands

6 Dutch Forensic Medical Association, Rotterdam, the Netherlands
- Mrs. Eleonora A. Landsmeer-Beker (Rivierduinen, GGZ $\mathrm{K} \& \mathrm{~J}$, Leiden, the Netherlands).

- Seraphinus P.H. Letmaath (GGD, Drenthe, the Netherlands).

- Mrs. Monique L'Hoir (GGD GHOR, the Netherlands).

- Jaap Mulder (Landelijke Werkgroep Wiegendood van de NVK).

- Mrs. Tatjana Naujocks (Community Health Service, Groningen, the Netherlands).

- Ype Schat (GGD GHOR, the Netherlands).

- Martin de Vries (GGD GHOR, the Netherlands).

- Frits Woonink (Department of Forensic Medicine, Public Health Service, region Utrecht, the Netherlands).

Publisher's note Springer Nature remains neutral with regard to jurisdictional claims in published maps and institutional affiliations. 